\title{
AS CONFIGURAÇÕES DO LAZER NA CIDADE DO SALVADOR E SUAS RELAÇÕES COM A CONSTITUIÇÃO DA UNIVERSIDADE FEDERAL DA BAHIA
}

Recebido em: 19/07/2016

Aceito em: 26/04/2017

\author{
Wilson de Lima Brito Filho \\ Coriolano P. da Rocha Junior \\ Universidade Federal da Bahia - UFBA \\ Salvador - BA - Brasil \\ Carlos Fernando F. da Cunha Junior \\ Universidade Federal de Juiz de Fora - UFJF \\ Juiz de Fora - MG - Brasil
}

RESUMO: O trabalho tem como questão central: Quais as relações entre a construção da Universidade Federal da Bahia (UFBA) e a fruição das vivências e ações no lazer soteropolitanos, no período entre 1945 e 1955? Objetivou-se investigar o processo histórico de constituição do lazer, em Salvador no período citado, especificamente a partir da formação da UFBA, bem como, perceber a repercussão dessa instituição, através das suas ações, com a organização do fenômeno lazer na cidade. Metodologicamente optamos por uma revisão de literatura que dialogasse com o contexto se utilizando de fontes históricas, jornais e revistas de época, notadamente o jornal $A$ Tarde. Como conclusão, entendemos que houve uma interface entre a construção da UFBA e a produção, incorporação de novas formas de lazer pela cidade.

PALAVRAS CHAVE: Atividades de Lazer. História. Educação.

\section{THE CONFIGURATIONS OF THE LEISURE IN THE CITY OF SALVADOR AND ITS RELATIONSHIP WITH THE CONSTITUTION OF THE FEDERAL UNIVERSITY OF BAHIA}

ABSTRACT: The work has as central question: What are the relations between the construction of the Federal University of Bahia (UFBA) and enjoyment of experiences and actions in soteropolitanos leisure, in the period between 1945 and 1955? This study aimed to investigate the historical process of formation of leisure in Salvador, in cited period, specifically from the formation of the UFBA, and realize the impact of this institution, through its actions, the organization of leisure phenomenon in the city. Methodologically opted for a literature review that could dialogue with the context using historical sources, newspapers and magazines of the time, notably the newspaper A Tarde. In conclusion, we believe that there was an interface between the construction of the UFBA and production, incorporating new forms of recreation for the city. 
KEYWORDS: Leisure Activities. History. Education.

\section{Introdução}

O presente estudo busca entender as possíveis relações entre a constituição de uma nova unidade acadêmica, a Universidade Federal da Bahia (UFBA), e os processos de experimentação das diversas formas culturais que se configuravam como possibilidades de lazer na e para a cidade, ou seja, buscamos entender a relação entre a construção da UFBA e a constituição do lazer em Salvador.

Nesse sentido apontamos que aqui entendemos cultura, como: “[...] um conjunto de valores, normas e hábitos que regem a vida humana em sociedade" (MELO \& ALVES JUNIOR, 2003, p. 26). Portanto, a cultura percebida de forma ampla, considerando o contexto da erudição na relação com as produções populares, o que estabelece nesse trabalho um pensamento que coaduna com o ideal previsto pelos "novos estudos culturais", em verdade, busca-se estabelecer as possíveis relações entre contextos e construções diferentes.

$\mathrm{Na}$ busca por estabelecer esse elo informativo, a principal percepção sensibilizadora para o estudo foi o seguinte questionamento: Quais as relações entre a construção da Universidade Federal da Bahia e o desenvolvimento e a fruição das vivências e ações no lazer soteropolitanos, no período entre 1945 e 1955 ? Esta questão nos remete ao entendimento da construção sócio histórica das relações entre o lazer, como fenômeno social e a UFBA, como espaço formativo, numa lógica que se circunscreve à formação humana, tendo como base o artigo 207 da Constituição de 1988

\footnotetext{
${ }^{1}$ Campo de investigação de caráter interdisciplinar que explora as formas de produção ou criação de significados e de difusão dos mesmos nas sociedades atuais. Os estudos culturais não se configuram exatamente como uma disciplina distinta, mas sim uma abordagem ampla dentro das disciplinas constituídas.
} 
(BRASIL, 1988) que indica a indissociabilidade de ensino, pesquisa e extensão. Portanto, uma formação pautada na constante relação entre Universidade e comunidades.

A partir desse problema, apontamos como hipótese a noção de que a UFBA, a partir de suas ações, especificamente as do campo da cultura, influenciou e, ao mesmo tempo, recebeu influência dos modos de lazer da cidade do Salvador, nas décadas de 1940 e 1950. Esta relação se evidenciou a partir das diversas formas de vivência e experimentação de práticas que possibilitaram, no cenário soteropolitano, o desenvolvimento de ações culturais diretamente ligadas à fundação dos cursos da UFBA, seus cursos livres e demais ações.

Essas relações estavam vinculadas às perspectivas de mudança que a própria cidade passava e o novo modelo de mundo que se buscava alcançar. Um modelo que substituía tudo o que era tradicional, lento e artesanal, entendidos por ultrapassados, pela velocidade, por ações que indicassem o progresso estabelecendo uma nova cultura (RISÉRIO, 2004).

Partindo desses elementos, nossa proposta de estudo objetivou investigar o processo histórico de constituição do lazer, em Salvador, entre os anos de 1945 e 1955 , especificamente a partir da formação da UFBA, assim como, perceber a repercussão dessa instituição, através das suas ações, na organização do fenômeno lazer na cidade.

Metodologicamente, optamos por uma revisão de literatura que dialogasse com o contexto e com os temas em foco, ou seja, estudos sobre a fundação da UFBA, o fenômeno lazer, a cidade e modernidade ${ }^{2}$. Ainda, na análise destas literaturas, as

\footnotetext{
${ }^{2}$ Entendemos que Salvador viveu diferentes fases de aspiração por uma modernidade. Assim, a aqui tratada é mais um momento, associada às condições contextuais da época tratada (1945-1955) e a constituição da Universidade.
} 
cotejamos com fontes históricas, específicas, jornais e revistas de época, notadamente o jornal - A Tarde -, por entendermos que este era o que melhor representava a conjuntura soteropolitana e seu cotidiano.

Barros (2004, p. 134-135), no que é tocante ao uso destas fontes, indica que:

A fonte histórica é aquilo que coloca o historiador diretamente em contato com o seu problema. Ela é precisamente o material através do qual o historiador examina ou analisa uma sociedade humana no tempo. Uma fonte pode preencher uma das duas acima explicitadas: ou ela é o meio de acesso àqueles fatos históricos que o historiador deverá reconstruir e interpretar (fonte histórica $=$ fonte de informações sobre o passado), ou ela mesma... é o próprio fato histórico. Vale dizer, neste último caso considera-se que o texto que está se tomando naquele momento como fonte que é já aquilo que deve ser analisado, enquanto discurso de época a ser decifrado, a ser compreendido, a ser questionado. É neste sentido que diremos que a fonte pode ser vista como 'testemunho' de uma época e como 'discurso' produzido em uma época.

Dessa forma, a tentativa foi a de desenvolver uma articulação entre os dados apresentados no principal jornal da época com o que se encontra na literatura, na tentativa de compreender a cidade no seu diálogo com a fundação da UFBA e as repercussões da instituição nos fazeres e lazeres soteropolitanos. Isto, através do testemunho ou discurso destas fontes, em específico na construção da cultura do fenômeno lazer no imaginário e cotidiano dos soteropolitanos.

Outro importante fator a observar é a opção em adotar embasamento na História Cultural, partindo da tentativa de apresentar retratos fidedignos do recorte temporal que incluam as impressões e acontecimentos que deem conta da realidade vivida. A História Cultural, como abordagem, funda uma percepção ampliada dos fenômenos, mas é importante entender que não se trata de um enquadramento do estudo e sim da opção de tornar a análise de dados fidedigna. Os historiadores culturais: "devem praticar a crítica das fontes, perguntar por que um dado texto ou imagem veio a existir, e se, por 
exemplo, seu propósito era convencer o público a realizar alguma ação" (BURKE, 2008, p.33). Portanto, a análise do contexto é repleta de vida, incluindo nos processos de interpretação os sujeitos e eventos históricos.

Por fim, também há que se falar no recorte temporal. A opção pelo período reside naquilo que o problema apresenta como ponto fulcral, ou seja, a tentativa de compreender o período imediatamente anterior e também posterior à criação da UFBA. A busca é por analisar a conjuntura cotidiana soteropolitana anterior a sua fundação e ainda, analisar as repercussões de sua instituição, observando a representação nos lazeres soteropolitanos a partir dessa criação, entendendo este como um período de efervescência cultural, como afirma Risério (2013).

A relevância do presente estudo está na busca do reconhecimento das produções cientificas das áreas em foco, bem como, nas relações, vivências e o acúmulo histórico que constituem o processo de formação cultural dos sujeitos e da interferência destes conhecimentos no alicerce e produção dos saberes e de práticas humanas, de forma a promover interações significativas que possibilitam uma percepção em torno desse fenômeno. Também é importante frisar a inexistência de estudos correlatos no estado da Bahia, o que confere a esse trabalho uma condição de originalidade e acresce ao mesmo maior importância. De forma concreta, buscamos entender as demandas apresentadas pelos sujeitos e diversas instituições sociais no período de tempo de uma década.

\section{Primeiras Rotas}

Na literatura existente sobre o período de criação da Universidade Federal da Bahia (UFBA) há a presença de vários panoramas que, em sua maioria, indicam os anos 1950 como tendo sido autênticos - anos dourados -. A literatura nos leva a entender que a tradicional sociedade baiana, mais especificamente a soteropolitana, direcionou-se a 
uma transformação que visava ligar essa cidade aos novos direcionamentos sociais, às efervescentes mudanças que se davam no período, no Brasil e no mundo.

Assim, Salvador sentiu o desejo, mais uma vez, de transformação, concentração e expansão dos espaços e com eles a reestruturação dos modos de vida próprios aos movimentos de modernidade. Sobre esta e um possível conceito, Kumar (1996) afirma que ela:

[...] extrai seu significado tanto do que nega como do que afirma. [...] a modernidade sente que o passado não tem lições para ela; seu impulso é constantemente em direção ao futuro. Ao contrário de outras sociedades, a sociedade moderna recebe bem e promove a novidade. É possível dizer que ela inventou a "tradição do novo" (p.473).

Nesse sentido, quando se fala de uma nova (con)formação de Salvador, identificamos que nas décadas de 1940 e 1950, a cidade foi tomada por uma séria de obras, que tentaram a dar uma cara nova: ruas, avenidas e mesmo bairros.

É importante frisar que esse processo de transformação acabou influenciando toda a dinâmica social, os modos de vida e as formas de lazer na capital baiana. Assim, podemos dizer que o movimento de criação da UFBA esteve diretamente ligado a esse processo de mudança, já que dominava, ao menos na ideia de uma elite, o indicativo de:

Tirar da rotina e do marasmo a música, a dança, o teatro e as artes de um modo geral é mexer nas estruturas sedimentadas e zelosamente cuidadas. E esse papel, subversivo, coube àqueles que vieram de outras plagas [...] que aportaram na Bahia no período em que o Reitor Edgard Santos construiu a experiência fundadora, humanista e aberta, da Universidade Federal da Bahia (LEÃO, 2006, p.91-92).

As práticas culturais, importantes e necessárias ferramentas para $\mathrm{o}$ desenvolvimento pessoal e social dos sujeitos, foram importantes recursos utilizados no processo de tentativa de ajustamento ao novo modo de vida. É importante observar que ao nos referirmos a práticas culturais, estamos reunindo a diversidade e diferenças 
próprias a uma grande quantidade de atividades envolvendo: “[...] ritos, modos simbólicos, atributos culturais da hegemonia, a transmissão do costume sob formas específicas das relações sociais e de trabalho" (THOMPSON, 1998, p. 22).

A UFBA, como uma nova instituição, teve papel importante na deflagração desse processo de mudança. Suas construções no âmbito das práticas culturais tiveram peso na sociedade soteropolitana, ajudando a construir outras vivências e sentidos, a vida social e aos lazeres da população. Vale ressaltar que para esse estudo, entendemos lazer como:

[...] uma dimensão da cultura constituída por meio da vivência lúdica de manifestações culturais em um tempo/espaço conquistado pelo sujeito ou grupo social, estabelecendo relações dialéticas com as necessidades, os deveres e as obrigações, especialmente com o trabalho produtivo (GOMES, 2004, p. 125).

Podemos perceber que o lazer e sua construção aparecem junto a tensões e contradições, e que não há consenso acerca do seu valor social, seus conceitos, legados e possibilidades. Situação que não vai divergir quando tratamos da cidade do Salvador.

A construção social do lazer não se dá de forma unilateral, não representa uma única realidade ou sentido. Desse modo, Marcellino (2002, p. 54) afirma que:

Todos os assuntos ligados aos estudos do lazer são bastante polêmicos. Para não fugir à regra, a questão da ocorrência histórica do lazer também é bastante discutida. Alguns autores consideram que, se os homens sempre trabalharam, também paravam de trabalhar, existindo assim um tempo de não-trabalho, e que esse tempo seria ocupado por atividades do lazer, mesmo nas sociedades chamadas "tradicionais". Para outros, o lazer é fruto da sociedade modernaurbano-industrial.

Por mais polêmico e polissêmico que seja o lazer, para nós é impossível esquecer o lugar que o fenômeno ocupa na estrutura das sociedades. No caso deste estudo que tem como recorte temporal o intervalo entre 1945 e 1955, buscamos analisar 
a relação entre a UFBA, como uma nova Instituição, com a tentativa de constituição de novas práticas de lazer. Isto por entendermos que esta Universidade se estruturou num momento em que a sociedade soteropolitana tentava acompanhar as mudanças no cenário mundial que envolvia uma crescente industrialização, um novo desenvolvimento das cidades, a mudança do modo de produção econômica, industrial, científica e cultural.

Neste sentido, também os espaços festivos e as ofertas de lazer passavam por uma modificação, conforme demonstram Melo \& Alves Junior (2003):

Podemos identificar uma busca paulatina por espaços públicos e uma organização progressiva do mercado de diversões, inicialmente com o teatro, depois com o esporte e o cinema e, já no início do século XX, com o rádio e mais tarde com a televisão (p.14).

Há, nesse sentido, uma busca alicerçada e influenciada por um cenário mundial, que serviu de referência para esse processo de modernização e cientificização social de Salvador, pautado na perspectiva de construção de uma cidade que queria ser moderna.

\section{Configurações do Campo do Lazer}

Pensar no fenômeno lazer é adentrar um emaranhado de significados e tempos, onde a palavra ou vocábulo utilizado para descrever o fenômeno ou ações similares, com características que se assemelham ao lazer vem adquirindo, historicamente, sentidos e significados dos mais diversos. E nesse sentido Dumazedier (2004, p.21) nos adverte:

O lazer é uma realidade fundamentalmente ambígua e apresenta aspectos múltiplos e contraditórios. Se não recorremos à língua de Esopo, talvez seja porque ela tenha sido demasiadamente utilizada para ainda expressar alguma coisa. Devemos, porém, desconfiar das definições a priori, das generalizações apressadas e das sínteses prematuras. 
O termo lazer e o seu conceito é palco de uma teia de significados e possibilidades de análise, sendo seu conceito debatido constantemente e por isso, alvo de constantes recriações.

Nesse sentido, não existem consensos, levando constantemente a uma confusão entre o lazer e demais fenômenos sociais, quando não de sua proposital descaracterização. Marcellino (2001, p. 19) afirma que:

Não existe um consenso sobre o que seja lazer entre os estudiosos do assunto, ou entre os técnicos que atuam nessa área, e muito menos no nível da população em geral. O fato, que traz dificuldade para abordagens do tema, programação de atividades e sua difusão, indica também que se trata de um termo carregado de preferências e juízos de valor.

Tentando aprofundar o reconhecimento do termo, alguns autores buscam o surgimento e derivação da palavra, como Melo (2010, p.15) que aponta:

A palavra leisure surgiu no século XIV, com o sentido de "oportunidade de fazer algo", derivada do francês medieval, leisour, que era originário do francês antigo leisir, que significava "ser permitido", que por sua vez vinha do latim licere, que significava "ser lícito". O conceito moderno de lazer, contudo parece ter claramente se sistematizado a partir do século XVIII.

É a partir dessa perspectiva que os estudos sobre o termo se asseveram, na verdade, são constantes não apenas as discussões sobre a origem do termo, mas sobre o próprio surgimento do fenômeno.

A despeito destes estudos:

[...] a palavra lazer e os diversos sentidos que carrega foram se incorporando à fala popular e tornando-se cada vez mais presentes, $o$ que significa certa tendência à valorização do conceito enquanto possibilidade de vivência cotidiana (MELO E ALVES JUNIOR, 2003, p.01). 
É importante observar que esse trato não surge por geração espontânea. Ora é entendido como um desdobramento de práticas e costumes que acompanham a humanidade desde a sua pré-história e vivido através de práticas que envolviam a diversão, contemplação, o descanso, ora é entendido como um fenômeno moderno diretamente relacionado à urbanização e à Revolução Industrial (MELO, 2010).

Portanto, para nossas discussões, compreender as configurações do lazer e o próprio fenômeno, significa contemplar sua origem, os processos e atos históricos, sociais e políticos que contribuíram com a sua construção no tempo e imaginário humano, bem como, seus usos na tentativa de uma análise que de fato circunscreva o lazer e suas relações. O lazer é um fenômeno vem ocupando cada vez mais espaço no cenário social atual.

Cabe salientar que também a sua constituição histórica encontra diferentes propostas e descrições, ora entendendo-o como fenômeno moderno, ora entendendo-o como um fenômeno que sempre permeou a vida do homem no mundo. Tomamos de pronto a decisão de pensar o lazer como um fenômeno moderno. Ao adotarmos para esse trabalho a corrente que o define a partir dessa dimensão, nos apoiamos em autores como: Bacal (2003); Mascarenhas (2004); Durmazedier (2004). Também em Marcellino (2001, p.14), que afirma:

[...] a partir da Revolução Industrial, com os avanços tecnológicos que acentuam a divisão do trabalho e a alienação do homem do seu processo e do seu produto. O lazer é resultado dessa nova situação histórica - o progresso tecnológico que permitiu maior produtividade com menos tempo de trabalho. Nesse aspecto, surge como resposta a reivindicações sociais pela distribuição do tempo liberado do trabalho, ainda que, num primeiro momento, essa partilha fosse encarada apenas como descanso, ou seja, recuperação da força de trabalho.

Importa observar que o lazer, inicialmente pensado como descanso para o uso do tempo livre, vai se configurando em novas possibilidades. E mais ainda, o lazer é 
incorporado à vida comum, sobretudo no momento em que se dá uma série de mudanças sociais advindas do avanço tecnológico, especificamente com: "o início da transição do estágio tradicional para o moderno [em] que se verifica a ruptura entre a vida como um todo e o lazer, fazendo com que esse adquira significação própria" (MARCELLINO, 2001, p.20).

De uma sociedade onde prevaleciam as relações personalizadas, na qual os sujeitos ditavam o ritmo da vida, passamos a relações que seguem um tempo outro, um tempo de máquina, veloz.

$\mathrm{Na}$ esteira da compreensão do lazer como fenômeno moderno, os próprios estudos passaram a existir e se estruturar a partir dos trabalhos de sociólogos, após Revolução Industrial e seus desdobramentos no universo do trabalho. Melo (2010) apresenta um processo de sistematização próprio à construção de lazer, tendo com fundamento essa corrente, através da observação da:

[...] articulação entre o desenvolvimento de um novo modelo econômico (que tem como um dos parâmetros centrais o modo de produção fabril), uma nova organização política (o fim do absolutismo e a gestão da ideia de Estado-Nação), a melhor estruturação de um conjunto de posições acerca da vida em sociedade (decorrentes do iluminismo e do liberalismo) e a nova conformação de classes sociais (o crescimento do poder da burguesia e o surgimento da classe operária) configuram um momento histórico marcado pela ruptura com o passado (p.15).

É língua corrente que a modernidade traz consigo essa transformação em vários campos, mas nos interessa neste instante o lazer que foi impactado pelas modificações no espaço urbano e mesmo nos estilos de vida adotados, passando a ganhar, de certa forma, centralidade.

Foi a partir deste delineamento, ou melhor, da luta por maior tempo livre, que se configurou o fenômeno lazer. 
No que diz respeito aos estudiosos que se aproximam do entendimento de que o lazer se dá, a partir da continuidade de outros períodos históricos, percebemos diferenças entre os fenômenos de outrora e o moderno fenômeno lazer, apesar de trazerem semelhanças com o que conhecemos hoje. Werneck (2000, p.21) assevera que:

[...] a palavra grega skhole, assim como a latina otium, significam toda e qualquer isenção da atividade política e não simplesmente lazer, embora ambas sejam também utilizadas para indicar cessação de trabalho. Entretanto, skhole não resultava da existência de um "tempo de folga" conquistado sobre o trabalho, mas era a possibilidade de abstenção das atividades ligadas à mera subsistência.

Podemos indicar que temos uma importante aproximação ou preparação para a construção da ideia de lazer e, nessa linha de pensamento, Melo e Alves Junior (2003, p.02) nos indicam que:

[...] observamos que a contínua busca de formas de diversão não significa ter sempre existido o que hoje chamamos por lazer, na medida em que tais formas de diversão (descanso e contemplação grifo nosso) guardam especificidades condizentes com cada época, que devem ser analisadas com cuidado. Por certo existem similaridades com o que foi vivido em momentos anteriores - e mesmo por isso devemos conhecê-los -, mas o que hoje entendemos como lazer guarda peculiaridades que somente podem ser compreendidas em sua existência concreta atual. $O$ fato de haver equivalências não significa que os fenômenos sejam os mesmos.

Pensar o lazer e a corrente que indica o surgimento do mesmo, pautado nessa continuidade histórica, traduz uma possibilidade que ocupa a minoria dos estudiosos e profissionais, mas não lhe remete maior ou menor importância.

O viés que adotaremos é do lazer para além dos interesses culturais, embora seja importante precisar que essa construção trata de entender o lazer para um direcionamento sensível, onde seu desenvolvimento favorece um

[...] processo de educação estética, de educação das sensibilidades, [que] no mínimo pode permitir aos indivíduos o desenvolver o ato de julgar e criticar a partir do estabelecimento de novos olhares (mais tolerante e multirreferenciais) acerca da vida e da realidade (MELO, 2002, p.105). 
Para Melo (2009, p.06), “[...] a racionalização de todos os setores da vida vai contrapondo cada vez mais as manifestações culturais como a esfera do fútil e o trabalho, em contraponto, gerador de renda e riqueza". Justo por isso, o lazer, como uma ação de educação estética, se impõem como uma possibilidade de rompimento com a condição humana de refém da produtividade.

Caminhando em outra linha de raciocínio, o acesso à cultura e ao lazer, precisa ter como base o cardápio diverso e a opção de livre escolha, num real exercício de liberdade e como nos diz Melo (2009, p.12), um desafio que “[...] se coloca a primeira vista, seria a sensibilização estética e a democratização da cultura erudita".

Isso vai dar num mundo que almeja se modernizar concomitante com a estrutura espacial, num ritmo de democratização que não tem como fundamento, apenas o aumento do repertório de atividades, mas sim um movimento em que democratizar o acesso ao lazer, se vincula a um tratamento democrático do espaço.

Então, não seria na classificação de atividades meramente pautadas na busca individual ou na democratização dos espaços, mas a partir da educação estética que aumentaríamos o leque de possibilidades, de prazeres para a vida (MELO, 2009) e é esta uma ação da UFBA, pois à época esta foi uma atitude tomada, ao menos quando da sua fundação, sob a direção do reitor Edgard Santos, cuja compreensão se pautava, segundo Risério, (2013, p.146) na:

Universidade enquanto instituição vanguardeira, inaugural, verdadeira ponta de lança da sociedade. O seu entendimento da necessidade de uma vida universitária livre e criativa, justapondo-se ao desenvolvimento econômico regional. Inovação estético-intelectual e atividades de prospecção do petróleo (que desapontavam no horizonte como possibilidade objetiva de uma redenção econômica da região) deveriam andar de mãos dadas. 
Dessa maneira, é possível percebermos que a ampliação própria do universo estético do lazer estava presente no imaginário e perspectivas do trato da cultura na nascente universidade.

\section{Atuação da Unversidade no Lazer: Rotinas e/ou Rupturas?}

Após tantas questões e discussões, não sabemos ao certo se seria a universidade atuante no lazer ou o lazer atuante na universidade. Ao tratar as construções do lazer, na relação entre cultura de vivência e vivida, Dumazedier (2004, p.35) afirma que "[...] estão sendo elaboradas transformações profundas e ambíguas no íntimo dos homens de todas as classes sociais, partindo de certas futilidades denominadas lazeres". Cabe sinalizar que o fenômeno traz consigo um despertar de maneiras de ser sociável, de agrupar o homem, como nunca acontecera na história (DUMAZEDIER, 2004). E prossegue o mesmo autor (2004, p. 47-48): “[...] são as organizações recreativas e educativas a forma mais original de sociabilidade desenvolvida pelo lazer [...] proliferaram em razão direta da expansão da industrialização e da urbanização”.

No caso do Brasil, há inicialmente uma apropriação festiva, como citam Melo e Alves Junior (2003, p.13-14):

O próprio contexto de modernização da sociedade brasileira vai contribuir para tornar importante, para as cidades em crescimento, os momentos de vida festiva. Podemos identificar uma busca paulatina por espaços públicos e uma organização progressiva do mercado de diversão, inicialmente com o teatro, depois com o esporte e o cinema e, já no início do século XX, com o rádio e mais tarde com a televisão.

Salvador, na Bahia, que perdera o seu lugar de destaque para o Rio de Janeiro, tentara, mais uma vez, alcançar a tão sonhada modernidade e, nesse sentido, a falta de produção de ciência e tecnologia revelava-se um entrave para a industrialização, para outra modernização, objetivo maior de um projeto de modernidade. Este sentimento 
soteropolitano de perda de status, de participação na sociedade é fato recorrente na capital da Bahia, ocorrendo, na verdade, desde a transferência da capital (ROCHA JUNIOR, 2011).

Pelo país sopravam ventos de modernidade e a Bahia encontrou possibilidades de fazê-lo, pelo desenvolvimento da vida acadêmica, pela ciência e pela ação no cenário cultural, na Universidade.

É importante relembrar a lição de Marques (2010, p. 71) sobre a Universidade:

A sociedade colocou a Universidade como agente do progresso científico e intelectual, para o atendimento de suas necessidades. Deixou de ser o lugar exclusivo para o ensino, absorveu a pesquisa, a cultura, a extensão e o novo formato para a sua pós-graduação.

A UFBA, para sua fundação, contou com um trabalho intenso de Edgard Santos. Nascido em Salvador, 08 de janeiro de 1894, filho de uma família de advogados ilustres da elite baiana, tornou-se médico respeitado, de renome, com circulação internacional e sempre alimentou o desejo de levar a Bahia a outro status. Para tanto, assumiu a tarefa de, a partir da criação da Universidade, fazer o estado alcançar uma modernização. (RISÉRIO, 2013)

Edgard Santos, com o apoio do Ministro de Educação - Souza Campos - se incumbiu de “[...] promover uma reviravolta na realidade local, extraindo-a da pasmaceira provinciana, para atirá-la por inteiro nas novas realidades do Brasil e do mundo" (RISÉRIO, 2013, p.107), contando para isso, com as possibilidades que a instalação de uma Universidade abriria na cidade.

Muito embora manifestações de cinema, teatro, literatura, música e artes plásticas fossem possibilidades culturais acessíveis aos baianos, a capital ainda vivia uma situação econômica desfavorável e, como dito, nutria um saudosismo de um dito 
tempo áureo, mesmo que na realidade vivesse com uma estrutura falida de equipamentos e espaços para o desenvolvimento cultural.

Dessa forma, a proposta de Edgard coadunava com a que estava presente na ideia de transformação de um estado de cultura provinciana para uma cultura que se quer moderna, como indica Laraia (1986, p.96):

[...] mudança que é inculcada pelo contato não representa um salto de um estado estático para um dinâmico mas, antes, a passagem de uma espécie de mudança para outra. $\mathrm{O}$ contato, muitas vezes, estimula a mudança mais brusca, geral e rápida do que as forças internas.

Nesse sentido, temos a criação de uma Universidade que vai caminhar na busca de uma produção cultural como princípio para a modernização do povo, através de um processo que não foi fácil, nem simples.

O período fruto desse trabalho nos brinda com um estágio de preparação e de adoção por Salvador de outro ideal de modernidade que traz consigo a busca por uma transformação estrutural, cultural, acadêmica enfim, uma adequação da cidade aos modelos externos na busca de recuperar seu brilho perdido. É importante sinalizar que o lazer enquanto fenômeno não permeava a realidade do soteropolitano da época, mas sim atividades que guardavam extrema relação com o fenômeno, ampliando o repertório cultural e artístico dos baianos por um lado e, por outro, a crescente luta, sobretudo dos estudantes, pela garantia de acesso a essas manifestações.

\section{Rotinas na Construção do Cenário Cultural Soteropolitano}

Compreender o advento de uma nova ideia de modernidade, advindo das relações entre Universidade e cidade e mais, suas repercussões no solo soteropolitano, implica uma série de análises, buscando perceber, nesse percurso, o lugar da cultura, 
dos patrimônios e demais produções na cidade, numa reflexão sobre o contexto e circunstâncias que marcaram a Salvador na época analisada.

Nesse sentido cabe verificar matéria do jornal $A$ Tarde $(11 / 07 / 1946$, p.3), de autoria de Rômulo Almeida, sob o título Universidades Regionais, nos apresentando o sentido e significado das Universidades:

\begin{abstract}
Universidade não é ornamento que a União conceda atendendo á influência política dos centros que a reclamam, ou que procura montar, com algum recurso de que dispuser, para honra e dignidade, se não quisermos dizer, para cartaz e farol do país, ou simplesmente aos seus instituidores. Universidade é centro vivo de pesquisas, de pensamento de criação, e de transmissão de conhecimento, indispensável a um sistema escolar, bem como ao desenvolvimento da economia e da cultura política. É um órgão de revelação da vida regional, de fixação, e de representação, de governo (...) A Universidade cumpre não apenas formar os clássicos profissionais (direito, medicina, engenharia) e os candidatos a modernas profissões superiores, mas preparar quadros do professorado secundário $\mathrm{e}$ primário, realizar estudos e pesquisas originais ligados mais diretamente aos cursos e estudos post-graduados, e ainda uma obra de divulgação e assistência científica á economia e á administração. Ela visa a formação do homem, a valorização do capital humano, mas essa formação e esta valorização do mais poderoso dos fatores da produção não é indiferente às coordenadas de um determinado meio geográfico e histórico.
\end{abstract}

A partir deste texto fica nítida a percepção ampliada que ocupa no imaginário de alguns intelectuais da época essa instituição de cunho formativo. E lógico, faz-se necessário compreender a percepção acerca do moderno e vale observar que a consolidação do moderno e da modernidade na construção social é alicerçada numa cidade que reconhece suas diferenças e vive uma dinâmica que vai, com o advento do urbano, desfazer a solidariedade entre o fixo e o humano, numa nítida relação entre a urbis e a civitas.

Em verdade, existe uma série de articulações que promovem as mudanças. Segundo Secchi (2009, p. 18), “[...] muitos fenômenos são fundamentalmente sobre 
determinados, ou seja, eles são o resultado de um número desmesurado de causas concorrentes. Entre essas, as transformações da cidade e do território.” Portanto, há um entrelaçamento de fatores estruturais, sociais e políticos, responsáveis pelas transformações no mundo moderno. Nesse processo, o desenvolvimento tecnológico e a necessidade de mão de obra, somados aos ideais iluministas, vão favorecer o processo de modernização.

É certo também que embora a ideia de lazer, desde a segunda metade do século XVIII, tenha ocupado os ideais europeus, numa nítida transformação ou busca de transformação dos recém-criados espaços de circulação e vida da urbis, o uso dessa palavra não se encontra presente nos cenários da Salvador na época desse estudo, embora traços, atividades e características do mesmo permeiem a realidade soteropolitana.

Tal compreensão pode ser vista no periódico $A$ Tarde $(01 / 02 / 1945$, p.2), na matéria de nome $\mathrm{O}$ baiano veraneia sem sair da capital. Nela se afirmava que

Domingo passado, a máquina fotográfica da "A TARDE" andou colhendo pelas nossas praias os instantâneos que acima estampamos. Essas cenas se reproduzindo domingo, quando, mais uma vez a população procurará, a vizinhança ao mar, veraneando, nas suas férias de um dia por semana.

Nesta matéria salta aos olhos o uso da praia e a consequente exposição corporal, fatos ainda não tão comuns à época.

Também apresenta a Salvador de época uma construção festiva constante, num misto de religioso e profano, constantemente retratado no periódico. São constantes as representações e notícias em torno da segunda-feira do Bonfim, dos gritos e festejos do carnaval, das festas joaninas. 
Um nítido campo cultural focalizado nas artes visuais, utilização de espaços, artes musicais, artes plásticas, compõem o repertório artístico cultural da Salvador, antes da fundação da Universidade Federal da Bahia. Cinema, música, teatro, frequência a praias, demonstram características de um estado latente do fenômeno lazer na sociedade soteropolitana, bem como uma teia vasta de atividades artísticas e culturais.

No que tange às compreensões sobre a UFBA, num primeiro momento, as notícias que relatavam a criação da Universidade, a indicavam ora como uma "[...] aspiração da cultura bahiana” (A Tarde, 03/04/1946, p.3 - A Universidade da Bahia.), ora como “[...] emancipação e engrandecimento do ensino da Bahia" (A Tarde, 09/04/1946, p. 2 - A Universidade da Bahia.). Ainda, vimos matérias que a apresentavam como a grande Instituição capaz de dotar a Bahia de uma cultura.

\begin{abstract}
A Bahia - tantas vezes o repetimos - tem nas suas paisagens históricas os traços necessários para ser a Coimbra americana. Mas é indispensável que se convença desse destino. As forças econômicas se distinguem pela auto-propulsão. Fazem-se por si. A riqueza material é as vezes mais considerada porque abandonada às diligências da iniciativa particular: tanto delas se desinteresse o Estado, tanto prosperam, solicitadas pelas leis inexoráveis da procura, da seleção, da oferta. Bem fazem os poderes públicos em socorrê-las. Mas, ai, deles se absorvidos pelas preocupações fiscais, deixarem de lado as cousas imponderáveis e ilustres da inteligência, que se ligam ao destino do povo e ao futuro e à glória da terra! A cultura é como a educação em todos os seus graus, um dever do Estado. Mas esse dever exige assídua e pródiga assistência. Gastar para o ensino é entesoirar (A Tarde, 13/04/1946, p.3 - A Universidade um ideal.)
\end{abstract}

É importante compreender também que as transformações foram sucessivas e que planos diferentes atuaram recepcionando modos genéricos, mas concomitantemente se apropriando das questões locais.

Em outra reportagem do jornal $A$ Tarde intitulada $\mathrm{O}$ que poderá realizar o teatro de estudantes da Bahia, há um indicativo da necessidade do ressurgimento do teatro de estudantes da Bahia, tendo como base o apelo ao 
Governo que se inicia do Dr. Guilherme Marback a quem hoje estão confiados os destinos deste grande Estado, a ele que não negará jamais estou bem certo, de auxiliar qualquer iniciativa neste sentido, pois, como bahiano amante de sua terra, espírito progressista, educado nos mais salutares princípios sociais, nos inspira, a todos nós, inteira confiança.

Ele não poderá ser indiferente a essa degradação da arte; a ele particularmente dirijo agora, meu palpitante apelo de brasileiro e bahiano, em nome das gloriosas tradições desta terra, que é também o vosso caricioso berço; em nome da Bahia intelectual, da Bahia artística, da Bahia culta, peço, não acompanhaes nesse caminho os passos dos últimos extintos Govêrnos ditatoriais contrários a beleza da arte lírico-dramática. (entrevista do Dr. Durval Guedes) (A Tarde, 08/05/1946, p.4.).

Assim, é necessário compreender a conjuntura vivida pela Cidade da Bahia (forma recorrente de se tratar a cidade do Salvador à época), no período previsto para nosso estudo, situando os acontecimentos e as relações entre sujeitos, ideologias e instituições.

Muito embora a visão e desenvolvimento de uma cultura acadêmica não permeassem o principal imaginário e realidade dos baianos, as ações no âmbito da arte (nas suas diversas manifestações) e cultura popular tinham um espaço reservado nas produções do município.

Um sentimento nostálgico ocupou os baianos que lutaram para construir uma nova realidade de crescimento, acompanhando o movimento moderno e seu desenvolvimento. Segundo Oliveira (1999, p.17):

A partir da década de 40 as artes e a arquitetura irão receber maior impulso em Salvador, com apoio de uma poderosa oligarquia local, fundada sobre o capital bancário e a circulação de excedentes produzidos pelo tabaco, pelo açúcar e, mais recentemente, pelo cacau. A Bahia, que havia ficado de fora na primeira investida industrialista, modernizadora, queria finalmente dar o salto.

Tal caminhar proporciona outro rumo ao trato soteropolitano de vida. Nesse sentido, vimos em Borges (2012) a compreensão de que a Bahia vive por criar um 
apego ao passado, tornando-se assim, um local onde o conservadorismo prevalece. Cabe frisar que mais do que um simples conservadorismo ou provincianismo havia uma decadência econômica na cidade da Bahia, o que inviabilizava a maioria dos planos para o atendimento do alcance áureo baiano. Na verdade:

Ao atingir seu quarto século de fundação, a cidade do Salvador (e toda a Bahia) encontrava-se em uma espécie de letargia, e podia se perceber, pelos resultados, em números, de uma rápida análise histórica, a situação de estagnação e decadência de sua economia. A virada da primeira para a segunda metade do século $\mathrm{XX}$ vai representar o marco inicial da construção e implementação de um projeto que visava inserir a Bahia e sua capital dentro do capitalismo brasileiro (BORGES, 2012, p.27).

Essa linha de raciocínio acabava por criar um sentido de contraste uma vez que se acreditava ou buscava-se fortalecer a condição de vanguarda brasileira própria ao estado da Bahia, o que Mangabeira veio a chamar de enigma baiano.

Vale ainda sinalizar que os olhares do país se voltavam para o Rio de Janeiro e para São Paulo, por causa do processo de industrialização que nestas cidades “[...] procuravam mão de obra barata. Ela procura nos migrantes nordestinos, os milhares de baianos, sergipanos, alagoanos, pernambucanos, paraibanos e cearenses que migraram para os estados do sul nos fins dos anos 1930 e 1940" (TAVARES, 2001, p.428). Tínhamos um desejo baiano, com movimentos contrários internos, uma condição socioeconômica interna desfavorável e uma preocupação principal com os estados de São Paulo e Rio de janeiro, cenário controverso e difícil para o desenvolvimento deste ideal de modernidade baiana.

Sobre o sentido cultural, a cidade vivia uma crescente onda de acesso aos clubes sociais que se apresentavam juntamente com outras instituições sociais como espaço para diversão como os Ternos da Pastorinha e Ternos das Flores no Clube Fantoches, festejos também no Iate Clube, no Cruzeiro da Vitória. 
Essas festas versavam juntamente com os festejos de rua, num misto de sagrado e profano, que se alargavam pela cidade em eventos temáticos e de época, como podemos citar os Ternos de Reis, que aconteciam principalmente na Lapinha, Fazenda Garcia, Ribeira - no Clube de Regatas de Itapagipe -, Tororó, Penha, Brotas (A Tarde, 07/01/1946). O ritmo era constante nos festejos e atrações culturais, logo após os festejos de Reis a cidade já se preparava para o Bonfim ( $A$ Tarde, 08/01/1946).

Portanto, a ambiência artístico-festiva e cultural da cidade da Bahia contava, nesse momento de busca por um ideal de modernidade, com um repertório de atividades diversas de cunho popular, aliava-se a estes festejos a crescente expansão do cinema, já presente em suas salas e também em tentativas de popularização dessa "arte" ( $A$ Tarde, $16 / 01 / 1946)$.

É fato que frente a esse turbilhão prosseguiam os preparativos, como nos apresenta notícia do $A$ Tarde, de 22 de maio de 1946, sobre os grupos de trabalho para instalação da Universidade. A matéria intitulada a "Organização da Universidade da Bahia”, apresentava a vinda do vice-reitor na Universidade do Brasil, para compor os grupos de trabalho em prol do planejamento da Universidade baiana.

Tal direcionamento passou a exigir um processo de transformação, de mudanças nos modos de ser dos baianos, visando atender ao projeto de modernidade que se asseverava no país e no mundo. Rocha Junior (2011), ao tratar de outro projeto de modernização da cidade, afirma que:

Se instalaram no Brasil iniciativas distintas de construção de projetos de modernidade. Essa busca foi dramatizada por tentativas de mudança de comportamentos e de efetivação de um novo cenário cultural, no qual as pessoas e cidades assumiam papéis e sentidos diferentes dos que se conhecia. Era necessário mudar os hábitos e os padrões que eram vistos como a representação de um atraso que ligava o país a um passado que se queria superar (ROCHA JUNIOR, 2011, p. 04). 
Entendendo que este dito se repete no que foi o recorte deste estudo, cremos que esta mesma conjuntura, mais uma vez, se deu em Salvador.

Nesta dimensão, o exterior era um modelo a ser seguido a qualquer custo e mais, as novas descobertas, inventos e mesmo a afirmação da ciência como um bem eram fatores que configuravam esse novo ideal de cidade.

A adequação aos ideais europeus e a uma nova ordem invadiu o Brasil e a Bahia, na busca por adequar a cidade aos ditames do movimento modernista e, portanto:

Essa leitura da modernidade, oferecida pelas transformações na infraestrutura urbana, é fértil na produção de discursos. A ela está indissociavelmente ligado o discurso do progresso, que atrai para si as campanhas de racionalização do espaço urbano, das vias públicas, das campanhas de regularização do trânsito e de higienização das feiras livres. É a cidade imaginada por engenheiros e arquitetos dentro da perspectiva de um urbanismo progressista, civilizador (GROBA, 2012, p.31-32).

Esse movimento que visava levar Salvador a um novo estágio recebeu forte impulso na Era Edgard Santos, por características e crenças próprias de Edgard e alguns baianos modernizantes da época que lutavam há tempos por um processo de modernização, a partir de um discurso nacional presente nesse momento histórico.

A Universidade então se apresentava como um farol para uma nova forma de fazer a sociedade, uma instituição que traçava os rumos do desenvolvimento da Bahia no cenário global, moderno e inovador. Nesse sentido, Dias (2013, p.169), apoiado em Elias (1994) afirma:

Conforme o sociólogo alemão Norbert Elias, "nenhum ser humano chega civilizado ao mundo e [...] o processo civilizador individual que ele obrigatoriamente sofre é uma função do processo civilizador social." Nesse sentido, a implantação das escolas e o ensino intelectual enquadravam-se na concepção civilizadora. 
Se ao menos nas primeiras quatro décadas novecentistas Salvadora permanecera imóvel, segundo Risério (2004, p.513): “[...] a partir de 1950, a Bahia irá ingressando progressiva, mas decisivamente - na dança do capitalismo moderno".

A criação da Universidade baiana seguia sendo notícia nos jornais. Matéria do $A$ Tarde tratava da instalação do Conselho Universitário, um dos preparativos para sua organização final, entendendo que isto significava um fortalecimento da intelectualidade soteropolitana.

Representa sem dúvida um acontecimento de nítida importância para o nosso meio, a constituição da "Universidade da Bahia" esse velho sonho, que durante tão longo tempo, foi alimentado pelas gerações de interessados no florescimento mental de nossa terra. Criada em princípios de Abril deste ano por lei federal juntamente com a de Pernambuco, a Universidade bahiana é, das duas a primeira que se organiza.

A brevidade com que foram e estão encaminhados os preparativos para sua instalação é devida ao eficiente trabalho da comissão de planejamento, que elaborou o seu arcabouço geral, secundada pelos diretores e professores de nossas Escolas no prosseguimento do referido trabalho, pela execução das diversas tarefas necessárias, até a instalação. E assim já no dia $1^{\circ}$ de Junho próximo vindouro se dará a solenidade para posse do Conselho Universitário, cuja reunião significa o início oficial de existência da nova entidade ( $A$ Tarde, $25 / 05 / 1946$, p. 2.)

A Universidade é apresentada como uma grande esperança e em torno dela surgiram expectativas para o renascimento da cidade da Bahia. Em verdade, digamos que a UFBA, a partir das ações de Edgard Santos, definitivamente, tem importante papel nesse processo, articulando cultura e economia na tentativa de retirar a Bahia de um pretenso estado de atraso.

Tamanho é o desejo em prol da UFBA que o jornal anuncia todo o processo de constituição, num nítido apoio para o ato de sua criação. Em 01 de junho de 1946, o $A$ Tarde (01/06/1946, p.2.), na notícia a instalação do Conselho Universitário. É importante observar que após essa instalação, os estatutos foram definidos, assim como 
a incorporação de escolas existentes, a eleição de reitor e vice-reitor e ainda, outras ações previstas no planejamento da nascente instituição.

Já no dia 03 de junho de 1946, o $A$ Tarde trouxe notícia ainda sobre a instalação do Conselho Universitário e da incorporação da Escola de Belas Artes e de um possível ingresso de uma Escola de Música. Ainda o mesmo jornal A Tarde (20/06/1946, p.2.) noticia a chegada à Bahia do então Ministro da Educação Souza Campos e comitiva que: "No dia 2 de Julho, acompanharão as solenidades comemorativas do transcurso da grande data bahiana, presidindo, à noite, no salão nobre da faculdade de Medicina, a seção para instalação da Universidade”.

E finalmente, após anos de luta, “[...] em 1946 foi criada a Universidade Federal da Bahia pelo Decreto-Lei $n^{\circ} 9.155$, de 8 de abril, e instalada no dia 2 de julho do mesmo ano" (TOUTAIN e SILVA, 2010, p. 50). Estava lançado o desafio do Ensino Superior na Bahia.

E assim, com a criação da UFBA, almejava-se outro olhar e mesmo a recuperação do brilho e civilidade capaz de elevar Salvador ao lugar de destaque que um dia ocupara. Uma tarefa difícil, mas que estrategicamente buscava se implantar:

Na época a cidade assiste à implantação de um programa educativo cultural sob a égide do reitor Edgard Santos, aquele homem que na província tem olhos para o mundo e marca com sua ação a identidade da Universidade, ao criar as escolas de arte, música, teatro e dança, tão decisivas para a formação de uma geração que nela encontra espaço para pensar e fazer as manifestações artísticas acontecerem num plano em que singularidade e pluralidade se somam na afirmação dessa identidade (LEÃO, 2006, p.107).

Uma identidade que tivesse a modernidade como base e que perpassasse por um modelo de civilidade desejado, para o alcance dos ideários apresentados pelo mundo 
desenvolvido numa constante busca de alcançar os modelos estabelecidos na Europa, base central dos olhares do Brasil e demais países do globo à época.

A ideia de ressignificar os lazeres e cotidiano cultural baiano ficou a encargo de Edgard Santos. Para isso ele contou com um grupo de profissionais de outros países, para segundo Leão (2006, p.91-92):

Tirar da rotina e do marasmo a música, a dança, o teatro e as artes de um modo geral é mexer nas estruturas sedimentadas e zelosamente cuidadas. E esse papel, subversivo, coube àqueles que vieram de outras plagas [...] que aportaram na Bahia no período em que o Reitor Edgard Santos construiu a experiência fundadora, humanista e aberta, da Universidade Federal da Bahia.

A ideia que permeava o momento baiano buscava ser reflexo de um atraso cultural, como se as produções internas não tivessem significação. Profissionais de fora do país, junto a Universidade Federal da Bahia, de acordo com Uzêda (2006, p.54), tendo como fundamento o conhecimento acadêmico, promoveram: “[...] transformações [que] se multiplicaram e afetaram a sociabilidade dos habitantes das cidades com forte repercussão na cultura, no lazer, no cotidiano e, por fim, nas mentalidades. A cidade redefiniu o ciclo da vida."

Importante observar que se construiu também a articulação entre estudantes da Bahia e demais cidades. Uma série de possibilidades começou a ser experimentada, no sentido de promoção do ideário de modernidade, como nos cita a matéria do Jornal $A$ Tarde. O texto aborda a participação de baianos no $\mathrm{X}$ Congresso Nacional de Estudantes, ocorrido no Distrito Federal e que provocou entendimento entre estes e os estudantes cariocas:

\footnotetext{
A Bahia vai receber em breve a visita do Teatro Universitário do Rio de Janeiro. A fim de articular entendimentos para a vinda do mesmo a esta capital, acha-se entre nós o acadêmico Paschoal Longo Junior, da Faculdade de Direito carioca e redator da rádio do Ministério de Educação (A Tarde, 23/08/1947, p.2.)
} 
É importante observar que há um estímulo à produção cultural, após a fundação da UFBA, o que se apresenta em linguagens variadas, e tem como base não apenas a produção cultural, mas a articulação acadêmica sob um forte movimento que observa todos os setores sociais.

No que diz respeito aos diálogos com os estudantes, no jornal $A$ Tarde, na matéria de título - A entrada dos estudantes nos cinemas - podemos ver nitidamente o processo de organização por parte desses universitários:

Considerando que a atual Diretoria vem sempre procurando atender aos justos anseios dos universitários bahianos empreendendo campanhas tais como: premiando os primeiros colocados nos exames universitários; concedendo empréstimos aos estudantes pobres; revivendo os cursos de línguas e instituindo um Curso de Vestibular; criando a campanha pró-liberação do Petróleo, ora apoiada e em andamento no Brasil inteiro pelas demais entidades estudantis; realizando noitadas universitárias; dando assistência médica, etc.,etc., e tendo iniciado com sucesso campanha de imediato e prático interesse para a classe, quais sejam a do Gabinete Odontológico, a ser doado pelo Ministério de Educação e Saúde, a do abatimento dos cinemas e a do "passe universitário" em apenas três meses de gestão, não poderia deixar de ouvir agora democraticamente, a voz da maioria da classe, e cor isso, accedeu ao pedido da mesma na não retirada de outro cartão, prevalecendo assim o das Escolas com o carimbo da U.E.B., conforme sugestão apresentada pelos próprios universitários. Consignamos aqui o nosso agradecimento ao espírito de colaboração e de boa vontade demonstrado pelos representantes dos exibidores cinematográficos de referência ao melhor modo de solucionar o problema (A Tarde, 10/04/1948, p.3).

Percebe-se uma gama de conquistas e batalhas da classe universitária, seja no âmbito do acesso aos bens culturais, assistência social, situação econômica brasileira, preparação universitária e popular, e prossegue a classe estudantil em importantes lutas coletivas.

É importante observar que o jornal $A$ Tarde trazia constantemente comunicações acerca da classe estudantil, num nítido sentido de parceria com a transformação e tão propalada modernização baiana. 
Dessa forma, a partir de sua organização inicial, podemos pensar que a UFBA em sua fundação foi uma experiência inovadora, com fundamento na cultura e no lazer. Ela buscou promover na cidade de Salvador a construção de novos modos de vida, articulando o desenvolvimento de um modelo econômico inovador, um novo formato de organização política, com estruturação diferenciada e melhorada de atitudes na vida cotidiana, além de uma nova articulação entre grupos e classes sociais, num nítido rompimento com o passado.

Leão (2006, p.105) chega a afirmar que no universo do teatro baiano:

Esses elementos inovadores vão se configurar no teatro na Bahia a partir da criação da Escola de Teatro da Universidade da Bahia, quando se dá de forma mais radical, em relação ao teatro que se fazia até então, a construção do espetáculo de maneira mais elaborada e artesanalmente mais complexa, a outra cena, tornando-se o fazer teatral uma ação afirmativa e vigorosa na vida cultural da cidade [...].

Em determinados momentos as críticas chegam mesmo a afirmar ser o teatro Universitário o único espaço de um teatro de qualidade, ou seja, toda a produção popular foi considerada sem qualidade, como nos cita Leão (2006, p.98), a partir de falas de jornalistas, como Carlos Falck:

Em 1961, Carlos Falck em sua coluna faz a seguinte afirmação: ... os amadores significam o mais descabido disparate de nossa cultura cênica. São grupos onde não existe a menor orientação estética e técnica. Fazem a coisa na base do improviso e não possuem, entre si, nenhum laço comum. [...] Os valores jovens que não podem ir para a Escola de Teatro, perdem-se, com o passar do tempo, nas estéreis recitações de textos mesquinhos (DIÁRIO DE NOTÍCIAS, 15 e 16.10.1961, p.98).

Os autores e as notícias promovem um rompimento com a realidade vivida, antes da fundação da Universidade, onde toda produção era tida como provinciana.

Vale também salientar que, mesmo assim, os caminhos da produção artística popular na cidade continuavam a ganhar rumos e diversas ações populares e ocorriam 
concomitantes ao desenvolvimento das ações do recém-criado mundo acadêmico universitário.

No imaginário das elites soteropolitanas era urgente promover um processo dinâmico, aliando Universidade e cultura. Isso foi feito através dos cursos livres e de um processo educacional pautado na estética e sensibilidade. Todas as ações com a articulação entre pesquisa, ensino e extensão voltariam a UFBA a essa construção tendo cultura, lazer e cidade (viva) como pano de fundo para esse processo. Numa "[...] comunicação espiritual do Brasil com o grande mundo" (RISÉRIO, 2013, p.149).

É fato que a Universidade cumprindo seu intento constrói uma série de ações e reconstrói pela via de movimentos de acadêmicos - movimentos de cunho políticoestrutural - e através dos cursos livres um acesso a uma nova cultura em consonância com a cultura do globo moderno. Abrindo suas produções para o público da cidade, num movimento de educação estética, “[...] trabalhando não somente com valores, mas, percepções e sensibilidades” (MELO e ALVES JUNIOR, 2013, p.64).

Foi nessa construção do acesso que a Universidade buscou interferir no trato da cultura e isso na tentativa de superação de um dito modelo provinciano, tendo a Universidade como lócus de produção e promoção. E neste tom prosseguiram as ações em outros Institutos e escolas.

\section{Caminhos em Aberto}

Após o estudo várias questões ficam postas e a nitidez acerca da necessidade de novas pesquisas se faz presente. Foi inegável o papel desempenhado pela Universidade Federal da Bahia, na tentativa de transformação da realidade ultrapassada da sociedade baiana, mas o universo de séculos de modos de fazer, certamente não se traduz numa 
transformação imediata. O investimento precisa ser contínuo, incansável e dialógico com todos os setores da sociedade.

Nos momentos analisados nesse trabalho, onde se estabeleceu uma proposta de projeto de modernização na Bahia, a UFBA, como uma nova instituição, teve papel importante na deflagração nessas transformações. Suas construções no âmbito das práticas culturais tiveram peso na sociedade soteropolitana, ajudando a construir outras vivências e sentidos, dando significados à vida social e aos lazeres da população.

Nessa linha de raciocínio, a aposta realizada e que nitidamente se fez presente no periódico analisado, até porque esse instrumento de imprensa traduz os anseios de a quem é endereçado e quem o escreve e mantém, a partir de falas que traduziam expectativas como: retirar do marasmo, promoção da intelectualidade, não se traduziram somente a partir de uma instituição e de suas ações, percebemos que essas falas contrariam o estado de efervescência cultural da cidade da Bahia, onde música, teatro, cinema, folguedos e festas populares, passeios às praças e praias, traduziam uma constante vivência dos baianos, seja em alguns destes espaços com acesso carimbado ou nos espaços de diálogo entre classes e grupos, na fruição de atividades e desenhos de percepções, sensibilidades e valores diversos.

Mas é fato que nessas primeiras rotas a sociedade soteropolitana tentava acompanhar as mudanças no cenário mundial que envolviam uma crescente industrialização, um novo desenvolvimento das cidades, a mudança do modo de produção econômica e industrial, além da científica e também, cultural, introduzia ou buscava introduzir outras rotinas nessa construção.

Concomitante com o processo formativo, a cidade passou por algumas transformações estruturais, abrindo espaço para os automóveis e com o crescimento de 
demandas, partindo do ideário de garantias sociais, vimos uma tentativa de democratização social que contou com apoio fundamental dos estudantes universitários. Estes tiveram um papel imprescindível, inicialmente na organização interna e na melhoria educacional universitária e mais a frente, na promoção de diálogos, trocas de informações e aproximações do cenário nacional, se envolvendo em manifestos, protestos e ações que atendessem as melhorias de vida da sociedade.

Outro fator que se apresentou na nossa escrita foi o fato de que, à época deste estudo, o Brasil ainda não traduzia o sentido das atividades artístico culturais, com o entendimento do sentido de lazer que se tem atualmente, já que o termo ainda não se fazia usual no país, elas representaram sim uma aproximação, tanto no formato estrutural, quanto nas discussões que traduziram uma transformação do cenário, rumo aos novos formatos, em consonância com o globo. Neste ponto, diria mesmo ter existido uma apropriação de outros fazeres das práticas já presentes, a partir de outro referencial, criando assim um processo de hibridização cultural em trocas mútuas e constantes. A Universidade com suas artes eruditas e a cidade com suas práticas populares.

A Universidade teve fundamental papel e isso foi observado, seja a partir dos periódicos ou nas literaturas consultadas. Ela pôde apresentar outros vieses do fazer cultural e produtivo numa projeção constante de um modelo de sociedade. A transformação da realidade baiana, um ideário de modernidade, é fruto de análises que vão se dar a partir da reverberação das ações dessa instituição no tempo, na observação da apropriação por parte do cenário cultural já existente e efervescente, por mais provinciano que tenha sido, e que tenha como referência esses novos modos e formatos de produção acerca da cultura e das artes. Entretanto, é inegável que embora o desejo de 
alguns grupos caminhe no sentido de imposição de um modo de fazer e ser, estes são sujeitos e transformados da mesma forma que transformam a cidade, o saber e cultura popular acrescenta ao saber e cultura erudita e lhe empresta peculiaridades que dão a produção artística cultural da cidade um tom único, local e carregado de identidade.

O campo de estudo é vasto e precisamos, sobretudo quando tratamos de fontes históricas, verificar aquilo que não foi publicado e que está presente nas fontes, portanto, necessário se faz a sua releitura com muitos olhares, na busca de reviver as mudanças, proposituras e influências da Universidade Federal da Bahia no contexto da Cidade da Bahia desta cidade na UFBA, focados na transformação das realidades vividas e incorporadas.

\section{REFERÊNCIAS}

BACAL, Sarah. Lazer e o universo dos possíveis. São Paulo: Aleph, 2003.

O BAIANO veraneia sem sair da capital. Atarde, Bahia, 01, fevereiro, 1945. p. 02.

BARROS, José D’Assunção. O campo da história: especialidades e abordagens. Petrópolis: Vozes, 2004.

BORGES, Eduardo. Renascença baiana: o cinema entre o discurso e a prática modernizadora na Bahia. Salvador: EDUNEB, 2012.

BRASIL. Constituição da república federativa do Brasil. Disponível em: $<$ http://www.planalto.gov.br/ccivil_03/constituicao/Constituicao.htm>. Acesso: 20 nov. 2014.

BURKE, Peter. O que é história cultural? 2. ed. Rio de Janeiro: Zahar, 2008.

CINEMA para o povo. Atarde, Bahia, 16, janeiro, 1946. p. 03.

O CONSELHO universitário será instalado a $1^{\circ}$ de Junho. Atarde, Bahia, 25, maio, 1946. p.02.

DECORRERAM animados os festejos de Reis. Atarde, Bahia, 07, janeiro, 1946. p.02.

IMPORTANTE etapa na formação da universidade (sobre instalação, hoje, do conselho universitário). Atarde, Bahia, 01, junho, 1946. p.02. 
DIAS, Olívia Biasin. Olhares estrangeiros: impressões dos viajantes oitocentistas acerca da Bahia, sua diversidade racial e seu potencial para alcançar a civilização. Salvador, 2013. 226f.: il. Tese (Doutorado) - Universidade Federal da Bahia, Faculdade de Filosofia e Ciências Humanas, 2013.

DUMAZEDIER, Jofre. Lazer e cultura popular. 3. ed. São Paulo: Perspectiva. 2004.

A ENTRADA dos estudantes no cinema (prevalecerá o cartão das escolas, com o carimbo da U.E.B.). Atarde, Bahia, 10, abril, 1948. p.03.

GOMES, Christianne Luce (Org.). Dicionário crítico do Lazer. Belo Horizonte: Autêntica, 2004.

GROBA, Tiago Santos. "Um lugar ao sol": Caderno da Bahia e a virada modernista baiana. 1948-1951, 2012. Dissertação (Mestrado) - Universidade Federal da Bahia. Disponível em: <http://repositorio.ufba.br/ri/handle/ri/11618>. Acesso em:18 set. 2014.

KUMAR, Krishan. Verbete Modernidade. In: OUTHWAITE, William e BOTTOMORE, Tom. Dicionário do pensamento social do século XX. Rio de Janeiro: Jorge Zahar, 1996.

LARAIA, Roque de Barros. Cultura: um conceito antropológico. Rio de Janeiro: Zahar, 1986.

LEÃO, Raimundo Matos de. Abertura para outra cena: o moderno teatro da Bahia. Salvador: Fundação Gregório de Mattos: EDUFBA, 2006.

MARCELLINO, Nelson Carvalho. Estudos do Lazer: uma introdução. 3. ed. Campinas: Autores Associados, 2002.

Lazer e humanização. 5. ed. Campinas: Papirus, 2001.

MARQUES, Maria Inês Corrêa. UFBA em memória: 1946-2006. Salvador: EDUFBA, 2010.

MASCARENHAS, Fernando. Lazer como prática de liberdade: uma proposta educativa para a juventude. 2. ed. Goiânia: Ed. UFG, 2004.

MELO, Victor Andrade de. Esporte e lazer: conceitos: uma introdução histórica. Rio de Janeiro: Apicuri, 2010.

; ALVES JUNIOR, Edmundo de Drummond. Introdução ao lazer. Barueri: Manole, 2003.

MELO, Victor Andrade de. Educação Estética e Animação Cultural: Reflexões. Licere, Belo Horizonte, v. 5, n.1, p. 101-113, 2002.

MELO, Izabel de Fátima Cruz. "Cinema é mais do que filme": a história do cinema baiano através das jornadas de cinema da Bahia dos anos 70. 2009. Dissertação de 
mestrado de história Social do Brasil na Faculdade de Filosofia e Ciências Humanas da Universidade Federal da Bahia. Disponível em: <http://www.ppgh.ufba.br/wpcontent/uploads/2013/10/Cinema-\%C3\%A9-Mais-do-Que-Filme.pdf $>$. Acesso em:18 set. 2014.

OLIVEIRA, Olivia Ferreira de. Notas sobre algumas páginas mais ou menos modernas. o "modernismo" na Bahia através das revistas. 1999, Revista RUA, v. 05, n. 01. Disponível em: <http://www.portalseer.ufba.br/index.php/rua/article/view/3130/2329>. Acesso em:15 jul.2014.

ORGANIZAÇÃO da Universidade da Bahia. Atarde, Bahia, 22, maio, 1946.p.03.

PARA PRESIDIR a instalação da Universidade (chega hoje á Bahia o sr. Ministro da educação). Atarde, Bahia, 29, junho, 1946. p. 02.

NA QUADRA das festas tradicionais. Atarde, Bahia, 08, janeiro, 1946. p.02.

O QUE PODERÁ realizar o teatro de estudantes da Bahia. Atarde, Bahia, 08, maio, 1946. p.04.

RISÉRIO, Antônio. Edgard Santos e a reinvenção da Bahia. Rio de Janeiro: Versal, 2013.

Uma história da cidade da Bahia. 2. ed. Rio de Janeiro: Versal, 2004.

ROCHA JUNIOR, Coriolano P. da. Esporte e modernidade: uma análise comparada da experiência esportiva no Rio de Janeiro e na Bahia nos anos finais do século XIX e iniciais do século XX. Tese (Doutorado). Programa de Pós-Graduação em História Comparada - Universidade Federal do Rio de Janeiro. 2011.

RÔMULO ALMEIDA. Universidades Regionais. Atarde, Bahia, 11, julho, 1946. p. 03.

SECCHI, Bernardo. A cidade do século vinte. São Paulo: Perspectiva, 2009.

TAVARES, Luiz Henrique Dias. História da Bahia. São Paulo: Editora UNESP: Salvador - BA: EDUFBA, 2001.

THOMPSON, E. P. Introdução: costume e cultura. In: THOMPSON, E.P. Costumes em comum. São Paulo: Companhia das Letras, 1998.

TOUTAIN, Lídia Maria Batista Brandão e DA SILVA, Rubens Ribeiro Gonçalves (Org.). UFBA: Do século XIX ao século XXI. Salvador: EDUFBA, 2010.

A UNIVERSIDADE da Bahia. Atarde, Rio de Janeiro, 03, abril, 1946 p. 03. A UNIVERSIDADE da Bahia. Atarde, Rio de Janeiro, 09, abril, 1946. p. 03.

A UNIVERSIDADE um ideal. Atarde, Rio de Janeiro, 13, abril,1946. p. 03. 
A UNIVERSIDADE já tem vida própria (como decorreu a solenidade de instalação do conselho universitário : incorporada a escola de Belas-artes e enunciado o possível ingresso de uma escola de música, com a fusão dos estabelecimentos existentes). Atarde, Bahia, 03, junho, 1946. p. 02.

UZÊDA, Jorge Almeida. O aguaceiro da modernidade na cidade do Salvador 19351945. Universidade Federal da Bahia, Faculdade de Filosofia e ciências Humanas, programa de pós-graduação em História. Tese (Doutorado). Salvador, 2006.

VIRÁ a Bahia um teatro de estudantes (temporada em dezembro - ultimam-se os entendimento para a apresentação - elenco e repertório). Atarde, Bahia, 23, agosto, 1947. p.02.

WERNECK, Christianne L. Lazer, trabalho e educação: relações históricas, questões contemporâneas. Belo Horizonte: Ed. UFMG; CELAR-DEF/UFMG, 2000.

\section{Endereço dos Autores:}

Wilson de Lima Brito Filho,

Rua do Paraíso, $n^{\circ} 237$

Condomínio São Bento, AP.903 C, Nazaré

Salvador - BA - 40.040-000

Endereço Eletrônico: wilsonlbfilho@gmail.com

Coriolano Pereira da Rocha Junior

Rua Alagoinhas 489 apt. 504 A - Rio Vermelho

Salvador - BA - 41.940-620

Endereço Eletrônico: coriolanojunior@uol.com.br

Carlos Fernando Ferreira da Cunha Junior

Rua Carlos Chagas 26 - São Mateus

Juiz de Fora - MG - 36.025-010

Endereço Eletrônico: carlos.fernando@ufjf.edu.br 